\title{
Human serum amyloid A protein
}

\section{Behaviour in aqueous and urea-containing solutions and antibody production}

\author{
Alistair F. STRACHAN,* Enid G. SHEPHARD,* Dirk U. BELLSTEDT, $\dagger$ Gerhard A. COETZEE $\ddagger$ \\ Deneys R. VAN DER WESTHUYZEN $\ddagger$ and Frederick C. DE BEER*§
}

\begin{abstract}
*Department or Internal Medicine, University of Stellenbosch Medical School, Tygerberg 7505, †Department of Biochemistry, University of Stellenbosch, Stellenbosch 7600, and †UCT/MRC Research Unit for the Cell Biology of Artherosclerosis, Department of Medical Biochemistry, UCT Medical School, Observatory 7925, South Africa
\end{abstract}

\begin{abstract}
Human serum amyloid A protein (apo-SAA) can be prepared by gel filtration of delipidated acute-phase high-density lipoprotein in the presence of urea. The resultant apo-SAA is soluble ( $>90 \%$ solubility) in a wide range of buffer solutions, with all of the six major isoforms of apo-SAA being equally soluble. In ureacontaining solutions the isoforms behave qualitatively differently in various urea concentrations, probably reflecting subtle primary-structure variations. The higher-pI isoforms are only completely unfolded at $>7$ M-urea. By immunizing with apo-SAA adsorbed to acid-treated bacteria (Salmonella minnesota R595), high-titre antibodies can easily be elicited in rabbits.
\end{abstract}

\section{INTRODUCTION}

During the acute-phase response in humans, highdensity lipoprotein (HDL) particles acquire serum amyloid A protein (apo-SAA), a polymorphic plasma protein with six major isoforms, as a prominent apoprotein [1-3]. The functional role of apo-SAA has not been elucidated, but it is implicated in the pathogenesis of reactive systemic amyloidosis. It is believed to be the precursor of amyloid A protein (apo-SAA minus $28 C$-terminal residues), which is the principal protein component of amyloid fibrils [4-7].

Initial preparative techniques for apo-SAA employed gel filtration in $10 \%(\mathrm{v} / \mathrm{v})$ formic acid [8] and were characterized by poor yields [9] and limited solubility of one or more of the apo-SAA isoforms [10].

As a necessary adjunct to our ongoing studies of the biology of human apo-SAA, we have developed techniques which permit the isolation of soluble apoSAA with a high yield of each of the isoforms. Here we present this methodology, explore the behaviour of apoSAA in aqueous and urea-containing solutions and describe the production of high-titre rabbit antisera which react with all the major isoforms.

\section{MATERIALS AND METHODS}

\section{Preparation of HDL}

For experiments relating to apoprotein solubility and for apo-SAA purification (see below), HDL was prepared, as previously described [1], from blood obtained (with informed consent and Ethical Committee approval) from a pool of patients experiencing an acute-phase response. For experiments relating to apo-SAA isoform distribution as a function of HDL density, HDL was further sub-fractionated into $\mathrm{HDL}_{2}$ [plasma density $(\rho)=1.063-1.13 \mathrm{~g} / \mathrm{ml}], \mathrm{HDL}_{3 \mathrm{~A}}(\rho=1.130-1.155 \mathrm{~g} / \mathrm{ml})$ and $\mathrm{HDL}_{3 \mathrm{~B}}(\rho=1.155-1.180 \mathrm{~g} / \mathrm{ml})$ by re-centrifugation of HDL $(\rho$ adjusted to $1.21 \mathrm{~g} / \mathrm{ml})$ into a linear $\mathrm{KBr}$ gradient $(\rho=1.11-1.21 \mathrm{~g} / \mathrm{ml})$ as previously described [3].

\section{Delipidation of HDL and solubility of apoproteins}

The solubility of the HDL apoproteins and of apoSAA isoforms was assessed at different $\mathrm{pH}$ values. A $5 \mathrm{mg}$ portion of acute-phase $\mathrm{HDL}_{3}$ containing all six major isoforms [pattern 1 [1] (protein concentration $5.95 \mathrm{mg} / \mathrm{ml}$ )] was delipidated by mixing with $10 \mathrm{ml}$ of ethanol/diethyl ether $(3: 2, \mathrm{v} / \mathrm{v})$ for $4 \mathrm{~h}$ at $-20^{\circ} \mathrm{C}$. The pellet obtained from centrifugation [SM-24 rotor (Sorvall, Newton, CT, U.S.A.); $\left.1000 \mathrm{~g} ;-20^{\circ} \mathrm{C}\right]$ was washed once with $10 \mathrm{ml}$ of diethyl ether $\left(-20^{\circ} \mathrm{C}\right)$ and recentrifuged. The apoprotein pellet was made into a diethyl ether slurry (vol. approx. $1.1 \mathrm{ml}$ ) and this was divided into 22 equal portions of which two were placed into separate $1.5 \mathrm{ml}$ Microfuge tubes as controls [11]. The remaining $2050 \mu \mathrm{l}$ portions were applied on top of separate $500 \mu \mathrm{l}$ volumes of the following buffers (in Microfuge tubes) and left overnight at $4{ }^{\circ} \mathrm{C}$ for evaporation of the residual diethyl ether to occur: Buffer A, $0.02 \mathrm{M}$-phosphate (0.02 M- $\mathrm{Na}_{2} \mathrm{HPO}_{4} / \mathrm{NaH}_{2} \mathrm{PO}_{4}$ buffer containing $0.001 \mathrm{M}$-EDTA and $0.15 \mathrm{M}-\mathrm{NaCl}$ ), pH 6.0; Buffer B, 0.02 M-phosphate, pH 6.4; Buffer C, 0.02 M-phosphate, pH 7.0; Buffer D, $0.02 \mathrm{M}$-Tris $(0.02 \mathrm{M}-$ Tris/ $\mathrm{HCl}$ buffer containing $0.001 \mathrm{M}-E D T A$ and $0.15 \mathrm{M}-$ $\mathrm{NaCl}$ ), pH 7.0; Buffer E, $0.02 \mathrm{M}$-Tris, pH 7.4; Buffer F, 0.02 м-Tris, pH 8.0; Buffer G, 0.02 M-Tris, pH 8.4. After overnight diethyl ether evaporation the buffer tubes were Microfuged $\left(10 \mathrm{~min}, 4^{\circ} \mathrm{C}\right)$. The protein contents of both supernatants and pellets from tubes containing Buffers B, E and $G$ were determined by the Lowry method [14]. Supernatants from replicate tubes (Buffers B, E and G) were analysed by using $5-20 \%-(\mathrm{w} / \mathrm{v})$-acrylamide

Abbreviations used: apo-SAA, serum amyloid A protein; HDL, high-density lipoprotein; apo-A-I and apo-A-II, apolipoproteins A-I and A-II; BSA, bovine serum albumin: $\rho$, plasma density.

$\S$ To whom correspondence and reprint requests should be sent. 
gradient gels containing $0.1 \%(\mathrm{w} / \mathrm{v})$ SDS after treatment of the samples with $5 \%(\mathrm{v} / \mathrm{v}) 2$-mercaptoethanol [15]. Gels were stained with Coomassie Blue and destained in $10 \%(\mathrm{v} / \mathrm{v})$ methanol/10\% (v/v) acetic acid solution. Protein bands [corresponding to apolipoprotein-A-I (apo-A-I), apolipoprotein-A-II (apo-A-II) and apoSAA)] were excised and the Coomassie Blue stain extracted in $25 \%$ (v/v) pyridine solution. The Coomassie Blue stain was quantified by measurement of the absorbance at $605 \mathrm{~nm}$ blanked against the average dye extracted from two equivalently sized portions of the acrylamide gel through which protein had not migrated $[1,3,9]$.

\section{Electrofocusing}

Supernatants (one sample from each; Buffers A-G) were mixed with an equal volume of $20 \%(\mathrm{w} / \mathrm{v})$ trichloroacetic acid solution and the protein pellets (obtained after centrifugation) were washed once with ice-cold acidified acetone and resuspended in $25 \mu \mathrm{l}$ of $1 \%(\mathrm{w} / \mathrm{v})$ sodium decyl sulphate $/ 7 \mathrm{M}$-urea $/ 5 \%$ (v/v) 2mercaptoethanol. Samples were electrofocused as previously described [I] for approx. $3000 \mathrm{~V} \cdot \mathrm{h}$ on acrylamide gels containing ampholytes in the following proportions: $20 \%$ (v/v) pH 3-10, 40\% pH 5-7 and 40\% pH 7-9. Protein bands were excised, and the pyridine-extracted Coomassie Blue dye was quantified (see above).

\section{Apo-SAA purification}

Since Buffer $\mathrm{G}$ was found to be the most efficient with respect to apoprotein solubility, HDL was delipidated at $-20^{\circ} \mathrm{C}$ with ethanol/diethyl ether $(3: 2, \mathrm{v} / \mathrm{v})$ (see above) and the protein pellet dissolved in Buffer $G$ containing $7 \mathrm{M}$-urea. The dissolved apoproteins were applied to a column $(1.6 \mathrm{~cm} \times 70 \mathrm{~cm}$ ) of Sephacryl S-200 (Pharmacia, Uppsala, Sweden) and eluted, at room temperature, in the same buffer. Acrylamide (5-20\%, w/v)-gel electrophoresis in the presence of $0.1 \%$ SDS of nonreduced aliquots of selected column fractions was performed to identify apo-SAA-containing samples. (Apo-A-I and apo-A-II samples can be similarly identified and purified by further gel filtration in Buffer $\mathrm{G}$ containing $7 \mathrm{M}$-urea and $0.1 \%$ 2-mercaptoethanol $[12,13]$. The relevant fractions were extensively dialysed against 1:10-diluted Buffer $\mathrm{G}$, without urea, at $4^{\circ} \mathrm{C}$ and the dialysate freeze-dried to approximately one-tenth of its original volume. The resultant apo-SAA solution was stored at $4{ }^{\circ} \mathrm{C}$ in the presence of $0.02 \%(\mathrm{w} / \mathrm{v}) \mathrm{NaN}_{3}$.

\section{Urea-gradient electrophoresis}

Urea-gradient electrophoresis was performed by the method of Creighton $[16,17]$ whereby a linear concentration gradient of urea was formed containing a shallow reverse acrylamide concentration gradient to counteract the viscosity effects of urea. For a 0-8 M-urea gradient, equal volumes of $11 \%(\mathrm{w} / \mathrm{v})$ acrylamide, $8 \mathrm{M}$-urea and $15 \%(\mathrm{w} / \mathrm{v})$ acrylamide without urea, both in $45 \mathrm{~mm}-$ Tris/25 mM-boric acid/0.8 mM-EDTA, pH 8.4, were mixed. The gels were cast in $(82 \mathrm{~mm} \times 82 \mathrm{~mm})$ glass cassettes, photopolymerized and turned through $90^{\circ}$ before insertion into a GE-4 gel-electrophoresis apparatus (Pharmacia) filled with the above-mentioned Tris/ borate/EDTA buffer. A $150 \mu \mathrm{g}$ portion of pure apoSAA in Buffer $G$ containing $20 \%(w / v)$ sucrose and a trace of Bromophenol Blue was applied to the top of the gel, and electrophoresis, with buffer recirculation, was performed at $10 \mathrm{~mA}$ until the protein had entered the gel, and then at $20 \mathrm{~mA}$ for $3 \mathrm{~h}$. Gels were stained with Coomassie Blue and destained in $10 \%$ methanol $/ 10 \%$. acetic acid solution.

\section{Electrophoretic pH titration curves}

For analysis of electrophoretic $\mathrm{pH}$ titration curves, electrofocusing gels were made with a trough running parallel with the direction of current flow [18]. Gels were electrofocused as described above and then turned through $90^{\circ}$ on the gel platform. The electrode wicks were cut away and new wicks applied before addition of $100 \mu \mathrm{g}$ of apo-SAA (in Buffer G containing $7 \mathrm{M}$-urea) to the trough. Gels were then electrophoresed at $600 \mathrm{~V}$ (constant voltage), for 25 min and processed as previously described [1].

\section{Rabbit anti-(human apo-SAA)}

Rabbits were immunized with purified human apoSAA complexed with acid-treated naked bacteria. Cultured Salmonella minnesota R595 bacteria [19] were phenol-killed (10 g of phenol//itre of culture fluid) and naked bacteria prepared' as previously described [20]. Apo-SAA (in Buffer G; protein concn. $1.5 \mathrm{mg} / \mathrm{ml}$ ) was added to freeze-dried naked bacteria $(1 \mathrm{mg} / \mathrm{ml}$; aqueous suspension) at a protein mass ratio of $1: 5$. The mixture was dried by rotary evaporation and the resultant complexes were resuspended in phosphate-buffered

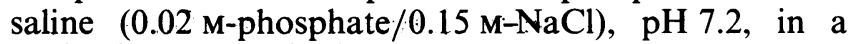
sonicating water bath at a protein concentration of 120 or $240 \mu \mathrm{g} / \mathrm{ml}$. Three mixed-strain rabbits were intravenously immunized with apo-SAA-naked bacteria complexes as follows: day $1,0.25 \mathrm{ml}$ of $120 \mu \mathrm{g} / \mathrm{ml}$; day 4 , $0.5 \mathrm{ml}$ of $120 \mu \mathrm{g} / \mathrm{ml}$; days $7,11,30,33$ and $36,0.5 \mathrm{ml}$ of $240 \mu \mathrm{g} / \mathrm{ml}$. Blood was drawn on day 18 and also 7 days after the last booster injection (i.e. day 43). Immune sera were analysed by Ouchterlony double immunodiffusion in agar against HDL from normal and acute-phase individuals. The IgG fraction of sera was prepared by using protein A-Sepharose columns (Pharmacia) according to the manufacturer's instructions. Immunogold staining of nitrocellulose blots of electrofocused normal and acute-phase HDL apoproteins developed with rabbit anti-(human apo-SAA) was performed as previously described [1] at a $1: 1000(\mathrm{v} / \mathrm{v})$ dilution of the primary antibody described herein in $0.1 \%(\mathrm{w} / \mathrm{v})$ BSA/Tris..

\section{RESULTS AND DISCUSSION}

\section{Apo-SAA isoforms and HDL density}

Six major isoforms of human apo-SAA can be identified by electrofocusing delipidated acute-phase HDL in the presence of urea [1]. Some individuals display all of these isoforms (with pI values of $6.0,6.4$, $7.0,7.4,7.5$ and 8.0 ; isoform pattern 1 ), whereas others apparently lack the pI 7.4 and 8.0 isoforms (pattern 2) or the pI 7.0 and 7.5 isoforms (pattern 3). Three apo-SAA mRNAs have recently been identified in one person [21], and each corresponding primary product could give rise to a proteolytically processed form lacking an $N$-terminal arginine residue. The relationship between these products and the six isoforms we identified remains to be determined.

The bulk of apo-SAA is associated with $\mathrm{HDL}_{3}$ [3]. However, apo-SAA can be found across the entire HDL 
Table 1. Distribution of apo-SAA isoforms within HDL

Delipidated HDL subfractions from a single HDL pool were electrofocused and the Coomassie Blue stain was quantified after extraction from the stained protein bands with $25 \%(\mathrm{v} / \mathrm{v})$ pyridine solution.

\begin{tabular}{|c|c|c|c|c|c|c|c|c|}
\hline \multirow{2}{*}{$\begin{array}{l}\text { HDL } \\
\text { fraction }\end{array}$} & \multirow{2}{*}{$\begin{array}{c}\rho \\
(\mathrm{g} / \mathrm{ml})\end{array}$} & \multirow{2}{*}{$\begin{array}{c}\text { Apo-SAA } \\
\text { isoform pI ... }\end{array}$} & \multicolumn{6}{|c|}{ Percentage of total colour yield } \\
\hline & & & 6.0 & 6.4 & 7.0 & 7.4 & 7.5 & 8.0 \\
\hline $\mathrm{HDL}_{2}$ & $1.063-1.130$ & & 28 & 35 & 13 & 7 & 12 & 5 \\
\hline $\mathrm{HDL}_{3 \mathrm{~A}}^{2}$ & $1.130-1.155$ & & 22 & 22 & 16 & 9 & 15 & 5 \\
\hline $\mathrm{HDL}_{3 \mathrm{~B}}$ & $1.155-1.180$ & & 22 & 27 & 18 & 11 & 16 & 6 \\
\hline
\end{tabular}

density spectrum. We analysed the distribution of apo-SAA isoforms in $\mathrm{HDL}_{2}(p<1.13 \mathrm{~g} / \mathrm{ml}), \mathrm{HDL}_{3 \mathrm{~A}}$ $(p=1.130-1.155 \mathrm{~g} / \mathrm{ml})$ and $\mathrm{HDL}_{3 \mathrm{~B}}(p=1.155-1.180 \mathrm{~g} /$ $\mathrm{ml}$ ) by electrofocusing portions of delipidated HDL from each of these density ranges, followed by quantification of the relative amounts of the individual isoforms in each sample by $25 \%-(\mathrm{v} / \mathrm{v})$-pyridine extraction of Coomassie Blue stain from the stained protein bands. The results (Table 1) show that there is no major difference in the apo-SAA isoform make-up of any of the HDL subfractions. Thus apo-SAA prepared from $\mathrm{HDL}_{2}$, $\mathrm{HDL}_{3}$ or total HDL will not be deficient in one or more of the apo-SAA isoforms. It has been reported that, in the moutse, apo-SAA is secreted from hepatocytes in a free form and then associates with circulating HDL particles [22]. Strould this pertain in humans then, in the light of the above data, one can suggest that each of the
apo-SAA isoforms has an equal affinity for each of the HDL particle types.

\section{Purification of apo-SAA}

Apo-SAA was separated from other HDL apoproteins by gel filtration over Sephacryl S-200 in the presence of $7 \mathrm{M}$-urea. The three principal apoproteins of acute-phase HDL (apo-A-I, apo-A-II and apo-SAA) have $M_{\mathrm{r}}$ values of 27000,17000 and 12000 respectively and would, as such, be poorly resolvable using Sephacryl S-200 [when chymotrypsinogen $\mathrm{A}\left(M_{\mathrm{r}} 25000\right)$ and ribonuclease $\mathrm{A}\left(M_{\mathrm{r}}\right.$ 13700 ) were analysed by gel filtration in phosphatebuffered saline on this column of Sephacryl S-200 they had elution volumes of 103 and $112 \mathrm{ml}$ respectively]. Urea, however, altered the apparent $M_{\mathrm{r}}$ of each of the apoproteins uniquely, resulting in an excellent separation of apo-SAA from apo-A-I and apo-A-II (Fig. 1). Under

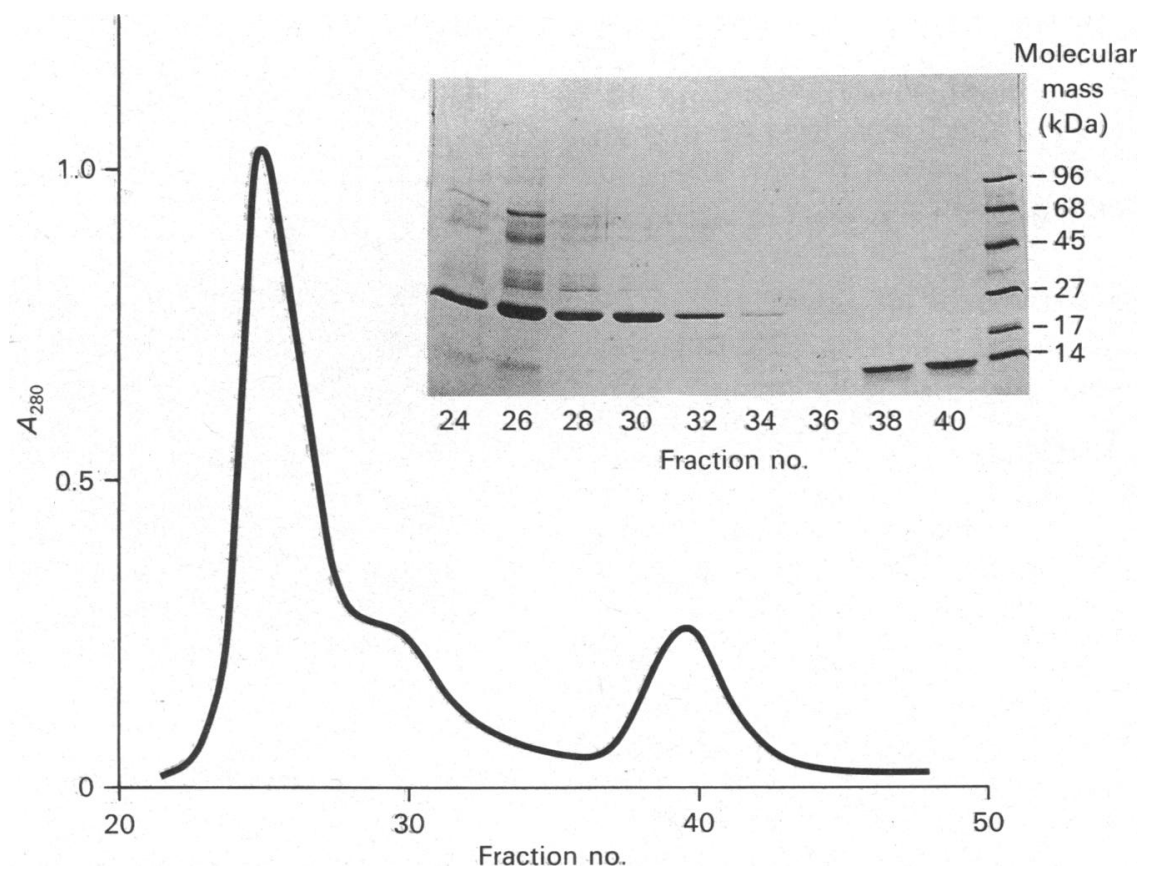

Fig. 1. Gel filtration of delipidated acute-phase HDL apoproteins on Sephacryl S-200

Gel filtration of apoproteins was performed in 7 M-urea. A $1.6 \mathrm{~cm} \times 70 \mathrm{~cm}$ column of Sephacryl S-200 was used. The flow rate was $4.24 \mathrm{ml} / \mathrm{h}$. Delipidated acute-phase HDL apoproteins $(20 \mathrm{mg})$ in a volume of $2 \mathrm{ml}$ were applied to the column. Apo-SAAcontaining fractions were identified by SDS $/ 5-20{ }^{\circ}{ }_{0}-(w / v)-$ polyacrylamide-gel electrophoresis (inset), and selected fractions were pooled for subsequent dialysis. 
Table 2. Acute-phase HDL apoprotein solubility

After solubilization in Buffers B, E or G, supernatants and pellets (obtained after centrifugation) were analysed by the Lowry protein determination method or by $25 \%(\mathrm{v} / \mathrm{v})$ pyridine extraction of excised Coomassie Blue-stained bands from SDS $/ 5-20 \%$ $(w / v)$-polyacrylamide-gel electrophoresis. All samples were analysed in duplicate. (Note that the HDL pool used for this experiment is different from that used to generate the data in Table 1.). The starting HDL had a supernatant SAA/A-I ratio of 0.72 .

\begin{tabular}{|c|c|c|c|c|c|}
\hline Technique & Protein in: & $\begin{array}{r}\text { Buffer ... } \\
\text { pH ... }\end{array}$ & $\begin{array}{c}\text { B } \\
6.4\end{array}$ & $\begin{array}{c}E \\
7.4\end{array}$ & $\begin{array}{c}G \\
8.4\end{array}$ \\
\hline Lowry protein assay & $\begin{array}{l}\text { Supernatant }(\mu \mathrm{g}) \ldots \\
\text { Supernatant }(\mathrm{mg} / \mathrm{ml}) \ldots \\
\text { Pellet }(\mu \mathrm{g}) \ldots \\
\text { Fraction soluble }(\%) \ldots\end{array}$ & & $\begin{array}{l}220 \\
0.44 \\
26.4 \\
88\end{array}$ & $\begin{array}{l}200 \\
0.40 \\
19.9 \\
90\end{array}$ & $\begin{array}{l}220 \\
0.44 \\
8.8 \\
96\end{array}$ \\
\hline $\begin{array}{l}\text { Pyridine-extracted } \\
\text { Coomassie Blue colour }\end{array}$ & $\begin{array}{l}\text { Supernatant } \\
\text { apo-SAA/apo-A-I-ratio ... }\end{array}$ & & 0.71 & 0.73 & 0.72 \\
\hline
\end{tabular}

these conditions, apo-A-I was eluted at the void volume of the column, whereas apo-SAA was eluted with an apparent $M_{\mathrm{r}}$ of $30000\left(K_{\mathrm{av}}, 0.40\right)$. Apo-SAA-containing fractions were selected on the basis of SDS/polyacrylamide-gel electrophoresis. These fractions were regel-filtered to remove contaminating apo-A-II, and the apo-SAA-containing samples were extensively dialysed against a $1: 10(\mathrm{v} / \mathrm{v})$ dilution of the eluting buffer minus urea. If the dialysis residue was then concentrated by freeze-drying to approximately one-tenth of its volume, apo-SAA remained soluble, provided that the sample was maintained at a temperature of less than $4{ }^{\circ} \mathrm{C}$. Concentrations of apo-SAA of up to $5 \mathrm{mg} / \mathrm{ml}$ were routinely obtained in this manner (results not shown). After a typical preparation procedure, $2.6 \mathrm{mg}$ of apoSAA was obtained from $20 \mathrm{mg}$ of acute-phase HDL starting material (apo-SAA content $=33 \% \equiv 6.6 \mathrm{mg}$ ). There was equal recovery of all isoforms. Previously, when apo-SAA was purified by gel filtration in $10 \%$ $(\mathrm{v} / \mathrm{v})$ formic acid solution and freeze-dried (to dryness), resuspension of the protein resulted in high losses, and protein concentrations above $2 \mathrm{mg} / \mathrm{ml}$ were unobtainable.

\section{Apoprotein solubility at different $\mathrm{pH}$ values}

When a diethyl ether slurry of HDL apoprotein was layered on various buffers with different $\mathrm{pH}$ values (pH 6.4, 7.4 or 8.4), a high percentage $(88-96 \%$ ) of the total protein remained soluble (Table 2). This method of achieving apoprotein solubility, whereby a gradual rehydration of the protein molecules is allowed to occur, has previously been described for other apoproteins [11]. Of the three buffers used, apoprotein solubility was greatest in Buffer $\mathrm{G}(\mathrm{pH}=8.4)$, as determined by the Lowry protein assay [14]. In all the buffers the apo-SAA/ apo-A-I ratio in the soluble material (see the Materials and methods section) closely reflected the apo-SAA/apoA-I ratio of the original starting HDL sample.

The solubility of the apo-SAA isoforms over an extended $\mathrm{pH}$ range (6.0-8.4) that covered the established pI values for all of the major apo-SAA isoforms [1] was studied by electrofocusing (Fig. 2). The relative contribution of each apo-SAA isoform to the total isoform complement was quantified by Coomassie Blue staining and remained similar in the supernatants from each of the buffers (results not shown). Furthermore, the relative proportions of the isoforms in all of the supernatants were not significantly different from those of the original starting HDL sample. Thus there was no evidence of selective isoelectric precipitation of individual isoforms. The isoforms of apo-SAA are only completely electrophoretically separable in the presence of relatively high concentrations of urea (see below) and the pI values assigned to the isoforms are those determined in urea (unfolded). The pI values of apo-SAA isoforms in their native state have not been established, but are unlikely to equate with those determined in urea. This represents one of the reasons why isoelectric precipitation may not have been seen. Other factors may include protein concentration, ionic strength (note that, with a $0.15 \mathrm{M}$ $\mathrm{NaCl}$ concentration, all of the buffers used in this study would have had approximately equal ionic strengths), and the formation of complex multimers between apoSAA isoforms $[3,10]$. It is clear, however, that all of the major apo-SAA isoforms, in contradistinction to a

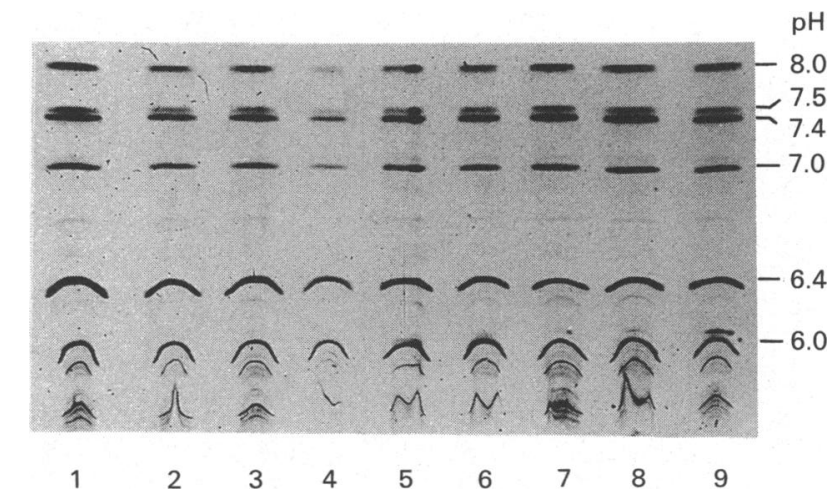

Fig. 2. Electrofocusing of solubilized apo-SAA isoforms

Acute-phase HDL apoproteins were solubilized in Buffers $A-G$, and portions of the supernatants (obtained after centrifugation) were analysed by electrofocusing in $7 \mathrm{M}$ urea on polyacrylamide gels. Tracks $2-8$, supernatants from Buffers A-G; tracks 1 and 9, sample of starting acute-phase HDL. Bands were subsequently stained with Coomassie Blue, excised, and the stain extracted with $25 \%(\mathrm{v} / \mathrm{v})$ pyridine solution (Table 2 ). 


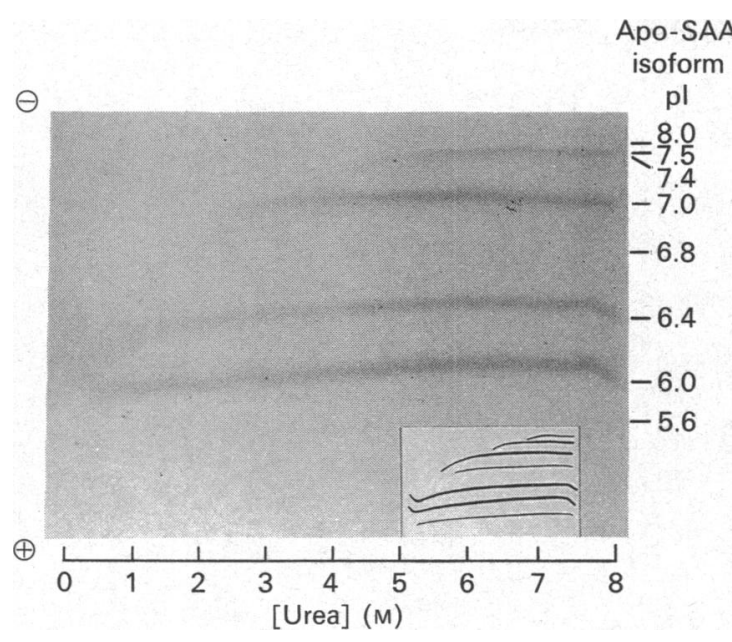

Fig. 3. Urea gradient gel of apo-SAA purified from pooled acutephase plasma

The pI 5.6 and pI 6.8 (minor) and pI 8.0 isoforms are not clearly visible by photography. The inset shows an artist's reproduction of the banding pattern, illustrating bands not clearly visible on the photograph.

previous report [10], are soluble over an extended $\mathrm{pH}$ range when solubilized in this manner.

\section{Effect of urea on apo-SAA}

Since the isoforms of apo-SAA are not separable in the absence of urea, we studied the effect of urea concentration on apo-SAA by using the method of Creighton $[16,17]$, whereby a protein sample is electrophoresed through an acrylamide gel comprising a urea concentration gradient at $90^{\circ}$ to the direction of protein migration. During the process of electrophoresis, ureaconcentration-dependent unfolding of the protein occurs, causing an increase in the hydrodynamic radius and a consequent slowing in the rate of migration due to increased molecular sieving. Additionally, alterations may occur in the electrophoretic mobility of the protein as a result of changes in its net charge due to exposure of ionizable groups or release of bound ions. Since apoSAA is a polymorphic protein [1], application of this technique to apo-SAA could be expected to yield a complex pattern of unfolding reactions. In all cases the protein was applied in the native state, and all ureainduced transitions occurred within the gel.

Over a concentration gradient from 0 to $8 \mathrm{M}$-urea the electrophoretic resolution of apo-SAA isoforms occurred such that the isoforms were only completely electrophoretically separable at urea concentrations in excess of $7 \mathrm{~m}$ (Fig. 3). The isoforms appeared to behave qualitatively differently with respect to urea concentration. On native 4-30\%-(w/v)-polyacrylamide-gel electrophoresis apo-SAA migrates with an $M_{\mathrm{r}}$ of 90000 [3]. From the urea-gradient-gel patterns observed here, it is likely that apo-SAA becomes monomeric at very low urea concentrations $(<0.5 \mathrm{M})$, with the resultant apparent increase in electrophoretic mobility being undetectable. Amplification of the low urea concentration range by the use of $0-4 \mathrm{M}$-urea gradient gels also failed to demonstrate the expected increase in mobility due to the urea-induced transition from multimeric to

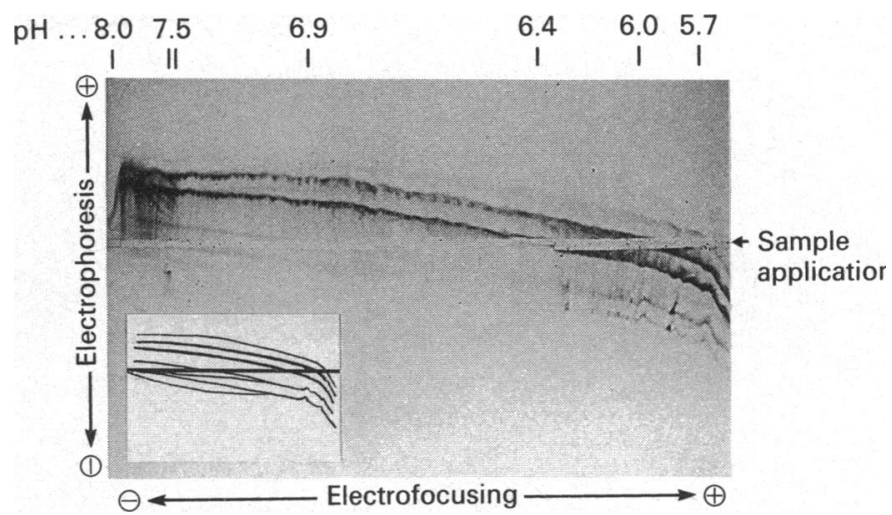

Fig. 4. Electrophoretic titration curve of apo-SAA purified from pooled acute-phase plasma

Stained bands, corresponding to the apo-SAA isoforms, cross the point of sample application $(\leftarrow)$ at $\mathrm{pH}$ values analogous to their $\mathrm{pI}$ values as determined by electrofocusing. The inset shows an artist's reproduction of the banding pattern, illustrating bands not clearly visible on the photograph.

monomeric species $[16,17]$ (results not shown). As the urea concentration increases, the observed patterns would be consistent with a continued, differential, ureainduced 'melting' of the apo-SAA isoforms. The fact that qualitative differences in the urea-induced melting of apo-SAA isoforms exist is interesting, since it may reflect important primary-structure variations. It is clear that a 7 M-urea concentration must be employed to ensure the electrophoretic separability of all apo-SAA isoforms.

Electrophoretic titration of pure apo-SAA across a pH gradient from 5.5 to 8.3 yielded further information on the behaviour of apo-SAA isoforms [18]. In the absence of urea, a satisfactory titration curve could not be obtained (results not shown). In the presence of $7 \mathrm{M}$-urea, titration curves of all the isoforms were observed (Fig. 4), crossing the starting trough at $\mathrm{pH}$ values closely corresponding to the $\mathrm{pI}$ values determined by electrofocusing [1]. Even in the presence of $7 \mathrm{M}$-urea, at $\mathrm{pH}$ values below their isoelectric points the $\mathrm{pI}>6.4$ apo-SAA isoforms showed differences in their electrophoretic mobilities relative to each other. Below approx. pH 6.4, apo-SAA (the pI-8.0 apo-SAA isoform) co-migrated with apo$\mathrm{SAA}_{7.5}$, and apo-SAA ${ }_{7.4}$ co-migrated with apo-SAA ${ }_{7.0}$. Thus at these relatively low $\mathrm{pH}$ values the apparent net charge differences between apo-SAA ${ }_{7.0}$ and apo-SAA and between apo-SAA ${ }_{7.5}$ and apo-SAA ${ }_{8.0}$ were abolished. Above pH 6.4, these apo-SAA isoforms were clearly resolved. The differences in relative electrophoretic mobilities of the $\mathrm{pI}>6.4$ isoforms are possibly a reflection of differences in primary structure which affect the titration curves of the ionization groups which are revealed in the unfolded state.

\section{Rabbit anti-(human apo-SAA)}

Specific antisera to apo-SAA have proved difficult to produce [23]. Recently, however, one group has been successful in producing a sequence-specific antiserum in rabbits [24]. The immunogen was a commercially synthesized decapeptide coupled to $N$-maleimidobenzoyl- $N$-hydroxysuccinimide ester-activated keyholelimpet haemocyanin. The peptide corresponded to 


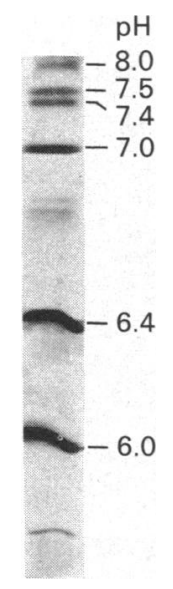

Fig. 5. Immunochemical analysis of the rabbit anti-(human apoSAA) serum

The Figure shows a nitrocellulose blot of electrofocused delipidated acute-phase HDL apoproteins (pattern 1) developed with the rabbit anti-(human apo-SAA) and immunogold-silver staining (gold-labelled goat anti-rabbit immunoglobulins).

residues 59-67 of human amyloid A protein plus an additional $C$-terminal cysteine residue, and the resultant antiserum was immunoreactive with amyloid $A$ protein and apo-SAA; it was, however, unsuitable for immunoprecipitation.

Apo-SAA (prepared as described herein) complexed to naked bacteria proved to be a potent immunogen. Hightitre precipitating antibodies were produced after the first booster injection (day 30) in all rabbits immunized. The immuno-absorbed antisera reacted with acute-phase HDL but not with HDL prepared from healthy individuals (even when normal HDL was used at twice the protein concentration of acute-phase HDL), giving a single line of immunoprecipitation and decorated all of the major isoforms of apo-SAA when these had been transferred (by pressure-blotting) from electrofocusing gels to nitrocellulose paper (Fig. 5) [1].

\section{Conclusions}

Studies of the biology of apo-SAA have been hampered by the belief that the protein was poorly soluble and by the apparent difficulty in achieving specific antibody production. In the present study we have shown that apo-SAA is soluble in buffers at physiological $\mathrm{pH}$ values and at suitable protein concentrations, all of the isoforms of apo-SAA being equally soluble. Apo-SAA can be readily purified in the presence of urea, and by adsorption to naked bacteria, high-titre specific precipitating antibodies can routinely be produced in rabbits.
This work was financially supported by the South African Medical Research Council, by the University of Cape Town and by the South African Arthritis and Rheumatism Association. The technical assistance of Ms. K. Lyner and Mrs. T. Greeff and secretarial skills of Mrs. B. Henstock are gratefully acknowledged.

\section{REFERENCES}

1. Strachan, A. F., De Beer, F. C., Van der Westhuyzen, D. R. \& Coetzee, G. A. (1988) Biochem. J. 250, 203-207

2. Bausserman, L. L., Herbert, P. N. \& MacAdam, K. P. W. J. (1980) J. Exp. Med. 152, 641-656

3. Coetzee, G. A., Strachan, A. F., Van der Westhuyzen, D. R., Hoppe, H. C., Jennah, M. S. \& De Beer, F. C. (1986) J. Biol. Chem. 261, 9644-9655

4. Lavie, G., Zucker-Franklin, D. \& Franklin, E. C. (1978) J. Exp. Med. 148, 1020-1031

5. Hoffman, J. S., Ericsson, L. H., Eriksen, N., Walsh, K. A. \& Benditt, E. P. (1984) J. Exp. Med. 159, 641-646

6. Meek, R. L., Hoffman, J. S. \& Benditt, E. P. (1986) J. Exp. Med. 163, 499-510

7. Hoffman, J. S. \& Benditt, E. P. (1983) J. Clin. Invest. 71, 926-934

8. Rosenthal, C. J., Franklin, E. C., Frangione, B. \& Greenspan, J. (1976) J. Immunol. 116, 1415-1418

9. Godenir, N., Jeenah, M. S., Coetzee, G. A., Van der Westhuyzen, D. R., Strachan, A. F. \& De Beer, F. C. (1985) J. Immunol. Methods 83, 217-225

10. Bausserman, L. L., Herbert, P. N., Forte, T., Klausner, R. D., McAdam, K. P. W. J., Osborne, J. C. \& Rosseneu, M. (1983) J. Biol. Chem. 258, 10631-10688

11. Mills, G. L., Lane, R. L. \& Weech, P. K. (1984) in Laboratory Techniques in Biochemistry and Molecular Biology (Burdon, R. H. \& Van Knippenberg, P. H., eds.), vol. 14: A Guidebook to Lipoprotein Technique, Appendix 3, pp. 463-471, Elsevier, Amsterdam

12. Edelstein, C., Lim, C. T. \& Scanu, A. M. (1972) J. Biol. Chem. 247, 5842-5849

13. Scanu, A. M., Lim, C. T. \& Edelstein, C. (1972) J. Biol. Chem. 247, 5850-5855

14. Lowry, O. H., Rosenberg, N. J., Farr, A. L. \& Randall, R. J. (1951) J. Biol. Chem. 193, 265-275

15. Laemmli, U. K. (1970) Nature (London) 277, 680-685

16. Creighton, T. E. (1979) J. Mol. Biol. 129, 235-264

17. Creighton, T. E. (1980) J. Mol. Biol. 137, 61-80

18. Weinberg, R. B. \& Spector, T. S. (1985) J. Biol. Chem. 260, 14279-14286

19. Schlecht, S., Ring, K., Kutschner, J. \& Eschweiler, W. (1968) Zentrolbl. Bakteriol. Parasitenk. Infektionskranckh. Hyg. Abt. 1. Orig. 206, 246-249

20. Bellstedt, D. U., Human, P. A., Rowland, G. F. \& Van der Merwe, K. J. (1987) J. Immunol. Methods 98, 249-255

21. Kluve-Beckerman, B., Dwulet, F. E. \& Benson, M. D. (1988) J. Clin. Invest. 82, 1670-1675

22. Hoffman, J. C. \& Benditt, E. P. (1982) J. Biol. Chem. 257, 10518-10522

23. Pepys, M. B. (1984) Br. Med. J. 288, 859-860

24. Grubob, A., Löfberg, H., Thysell, H., Ljunggren, L., Olsson, T., Skinner, M., Shirahama, T. \& Cohen, A. S. (1987) Scand. J. Clin. Lab. Invest. 47, 619-626 